\title{
GAMBARAN DURASI BERMAIN VIDEO GAME DAN TAJAM PENGLIHATAN PADA ANAK USIA SEKOLAH DI WARNET GO NET
}

\author{
Arief Witjaksono $^{1)}$, Dea Purnama Sari ${ }^{2)}$ \\ ${ }^{1)}$ Dosen Program Studi Diploma Refraksi Optisi STIKes Dharma Husada Bandung \\ ${ }^{2)}$ Mahasiswa Program Studi Diploma Refraksi Optisi STIKes Dharma Husada Bandung \\ Awicaks07@yahoo.co.id \\ Deapurnamasari05@gmail.com
}

\begin{abstract}
Abstrak
Bermain video game dapat memicu terjadinya penurunan tajam penglihatan pada anak-anak maupun orang dewasa baik secara langsung maupun tidak langsung yang menyebabkan aktivitas melihat dekat semakin meningkat. Durasi yang dianjurkan tidak melebihi 2 jam setiap harinya. Bila terlalu lama mata terpapar layar monitor akan menyebabkan kelainan refraksi. Tujuan penelitian ini yaitu untuk mengetahui Ketajaman Penglihatan dan Durasi Bermain Video Game Pada Anak Usia Sekolah di warnet Go Net. Jenis penelitian ini mendeskipsikan secara kuantitatif dari hasil pemeriksaan tajam penglihatan dan durasi bermain video game pada anak usia sekolah. Populasi pada penelitian ini adalah anak-anak usia sekolah yang bermain game dengan metode acidental sampling selama dua minggu dan didapatkan sampel sebanyak 45 orang. Hasil pada penelitian ini menunjukan bahwa tajam penglihatan yang tidak normal terbanyak pada kategori lama dalam durasi bermain game sebanyak 16 orang $(72.7 \%)$ untuk mata kanan dan sebanyak 15 orang $(68.2 \%)$ dan tajam penglihatan normal terbanyak pada kategori tidak lama sebanyak 19 orang (82.6\%) untuk mata kanan dan mata kiri.Disarankan untuk anak agar mengurangi durasi bermain game untuk menjaga kesehatan mata terutama tajam penglihatan mata.
\end{abstract}

Kata kunci : Durasi, Video Game, Ketajaman Penglihatan

\begin{abstract}
Playing video games can divert the sharp decline in children or adults both directly and indirectly which causes activity. The recommended duration should not exceed 2 hours per day. If exceeding, the eyes are exposed to the monitor screen and this may cause refractive abnormalities. The purpose of this research is to examine the visual acuity and the video game playing duration in school-age children at the Go Net internet cafe. This type of research is quantitatively descriptive of the results of sharp visual nspection and the duration of playing video games in school-age children. The population in this research consisted of 45 school-age children who played games in the research locus. This research used accidental sampling method and the research was conducted in two weeks. The analysis result showed that the most abnormal visual acuity was found among those with the long video game playing duration as many as 16 people (72.7\%) for the right eye and 15 people (68.2\%) and the most normal visual acuity was found among those with the short video game playing duration as many as 19 people (82.6\%) for the right eye and the left eye. Based on the research findings, it is recommended that the children reduce the duration of playing the games to maintain the health of their eyesight.
\end{abstract}

Keywords: duration, video game, visual acuity 


\section{PENDAHULUAN}

Gangguan penglihatan merupakan masalah kesehatan yang penting, terutama pada anak, mengingat $80 \%$ informasi selama 12 tahun pertama kehidupan anak didapatkan melalui penglihatan, pada tahun 2013 prevalensi gangguan ketajaman penglihatan pada anak usia sekolah di Jawa Barat sebanyak $0,8 \%$. Prevalensi visus lebih banyak pada anak yang ada di daerah pedesaan daripada perkotaan, hal tersebut ditunjukkan berdasarkan data Riskesdas tahun 2013 di mana proporsi visus pada anak usia sekolah di perkotaan sebesar $0,8 \%$ sedangkan di pedesaan sebesar 1,1\% (Rudhiati, Apriany, \& Hardianti, 2015).

Di era digital saat ini, anak-anak sudah mahir dalam menggunakan teknologi baik handphone, laptop maupun komputer. Anakanak yang gemar bermain game biasanya bermula dari rasa penasaran yang sangat tinggi terhadap sesuatu hal contoh nya pada game online yang sekarang sedang meningkat dikalangan anak-anak bahkan sampai orang dewasa.

Bermain game mempunyai sisi positif dan sisi negatif. Pada sisi positif anak-anak di usia sekolah menggunakan game sebagai salah satu cara menghilangkan rasa jenuh dalam belajar atau rasa bosan, sedangkan pada sisi negatif bermain game dapat menyebabkan lupa waktu, malas, tidur tidak teratur, kecanduan dan tajam penglihatan menurun. kurangnya perhatian mengenai gangguan penglihatan khususnya pada anak sekolah turut memicu terjadinya kelainan refraksi.

Berdasarkan hasil penelitian Caterina Rechichi, didapatkan timbulnya efek kelelahan visual dari penggunaan smartphone pada 22 orang dewasa yang sehat. Kelelahan visual diinduksi dengan menempatkan posisi smartphone berjarak $40 \mathrm{~cm}$ dari mata dan digunakan selama 1 jam secara continue (Caterina Rechichi, MD; Gilda De Mojà, MD, Pasquale Aragona, MD, PhD. 2016).

Screen time menurut Wong Et Al (2009) dalam Kairupan (2012) didefinisikan sebagai durasi waktu yang digunakan untuk melakukan screen-based activities atau aktivitas didepan layar kaca media elektronik tanpa melakukan aktifitas olahraga misalnya duduk menonton televis atau video, bermain komputer, maupun bermain permainan video (Porotu, Joseph, \& Sondakh, 2014).

Menurut Putri (2014) durasi adalah rentang waktu atau lamanya sesuatu yang sedang berlangsung, jadi yang dimaksud dengan durasi bermain video game adalah lamanya seseorang bermain video game. Hal tersebut didukung oleh Ester (2013) bahwa durasi yang dianjurkan anak dan remaja dalam bermain video game yaitu tidak melebihi 2 jam setiap harinya. Bila terlalu lama mata terpapar sinar radiasi yang dihasilkan dari layar monitor akan menyebabkan penglihatan dekat mata akan terus fokus sehingga ketika melihat jauh mata akan kehilangan fokus. Hal tersebut jika 
JURNAL SEHAT MASADA VOLUME XV

dibiarkan dalam jangka waktu panjang dan secara simultan akan menyebabkan turunnya tajam penglihatan dan menyebabkan seseorang mengalami kelainan refraksi (Rudhiati, Apriany, \& Hardianti, 2015).

Proses durasi mempengaruhi ketajaman penglihatan menurut Pravita (2010) disebabkan karena gelombang - gelombang pada layar monitor yang terlalu lama dilihat dapat maka sinar - X, Sinar ultraviolet, Gelombang mikro (microwave), Radiasi elektromagnetik frekuensi sangat rendah (Very Low Frequency /VLF) dan Radiasi elektromagnetik frekuensi amat sangat rendah (Extremely Low Freqierncy/Elf) gelombang tersebut akan ditangkap oleh kornea mata, kemudian cahaya tersebut diteruskan menuju lensa, lensa tersebut dapat rusak khususnya lensa mata pada anak usia sekolah karena secara fisiologis saraf mata anak masih rentan kerusakan akibatnya tajam penglihatan menurun. Penurunan ketajaman penglihatan tersebut tergantung dari lamanya durasi paparan dengan layar monitor sehingga pada saat bermain video game dianjurkan untuk tidak melebihi 2 jam setiap harinya (Rudhiati, Apriany, \& Hardianti, 2015).

Jika mata terlalu lama terpapar sinar radiasi yang dihasilkan dari pencahayaan layar komputer berpotensi mengalami Computer Vision Syndrome (CVS) yang dapat mempengaruhi tajam penglihatan. American Optometrist Association mendefinisikan CVS sebagai kumpulan gejala akibat penggunaan komputer yang terlalu lama yaitu dapat berupa mata lelah, sakit kepala, mata kering penglihatan buram, nyeri pada leher dan bahu adapun dampak secara sosial yaitu game online membuat remaja menjadi acuh dan kurang peduli dengan lingkungan. Selain itu permainan game online (Prot, Anderson, Gentile, Brown, \& Swing, 2014).

\section{METODOLOGI PENELITIAN}

Penelitian ini menggunakan metode statistik deskriptif, bertujuan untuk mendeskriptifkan atau memberikan gambaran secara kuantitatif dari hasil pemeriksaan tajam penglihatan dan durasi bermain video game pada anak usia sekolah di Warnet Go Net.

Populasi penelitian adalah seluruh anakanak usia sekolah yang bermain game di warnet Go Net, kota Kuningan yaitu sebanyak 45 orang. Sampel yang digunakan dalam penelitian ini adalah sampel jenuh/total sampling dengan menggunakan metode accidental sampling sebanyak 45 anak yang semua berjenis kelamin laki-laki dengan rentang usia 8 tahun - 18 tahun dan jenjang pendidikan dari SD sampai perguruan tinggi.

Kriteria anak emetropia dan ametropia, akan diuji menggunakan Snellen Chart dengan minimal melakukan pengulangan pengukuran sebanyak 2 kali untuk meminimalisir kesalahan bias hasil pemeriksaan tajam penglihatan.

Instrumen dalam penelitian ini menggunakan lembar kuesioner yang berisi 6 pertanyaan tentang lamanya durasi bermain 
dan lembar observasi berisi kolom nama, usia, visus sebelum bermain, durasi lama bermain game, visus sesudah bermain game, dan keterangan kategori yang berguna untuk menilai masing-masing hasil pemeriksaan ketajaman penglihatan pada anak-anak usia sekolah yang bermain game di Warnet Go Net, Kota Kuningan.

Metode pengumpulan data pada penelitian ini peneliti menggunakan pengumpulan data primer, pengumpulan data dilakukan di warnet Go Net Kuningan, dengan langkah pertama peneliti memberikan promosi terhadap konsumen/responden yang berkunjung di warnet tersebut selama kurun waktu 2 minggu . Perolehan data dilakukan dengan pemberian tambahan free bermain game satu jam, lalu diberikan lembar inform concern dan kuesioner terlebih dahulu kepada responden, dimana pertanyaan kuesioner berisi tentang dimulai dari tahun berapa responden bermain, berapa hari dalam seminggu responden bermain dan berapa jam responden bermain dalam sehari, selanjutnya dilakukan pemeriksaan tajam penglihatan dengan pengulangan 2 kali untuk menghindari terjadinya kesalahan bias. dan hasil pemeriksaan di masukkan kedalam bentuk lembar observasi cara ini dilakukan untuk mengungkap atau menjaring informasi kuantitatif dari responden sesuai lingkup penelitian dengan pengamatan dan pencatatan secara sistematik terhadap gejala yang tampak pada objek penelitian.

Analisis statik yang digunakan dalam penelitian ini adalalah dan analisis univariat (deskriptif) menjelaskan atau mendeskripsikan karaketeristik setiap variabel penelitian

\section{HASIL DAN PEMBAHASAN}

\section{A. Hasil Penelitian}

Tabel 1 Distribusi Frekuensi Durasi Bermain Video Game

\begin{tabular}{|c|c|c|c|}
\hline No. & $\begin{array}{c}\text { Total Jam } \\
\text { Bermain Game } \\
\text { (jam) }\end{array}$ & Jumlah & Persentase \\
\hline 1. & 96 & 1 & 2,2 \\
\hline 2. & 384 & 1 & 2,2 \\
\hline 3. & 864 & 1 & 2,2 \\
\hline 4. & 1296 & 1 & 2,2 \\
\hline 5. & 1344 & 1 & 2,2 \\
\hline 6. & 1920 & 2 & 4,4 \\
\hline 7. & 2592 & 2 & 4,4 \\
\hline 8. & 2688 & 1 & 2,2 \\
\hline 9. & 3072 & 1 & 2,2 \\
\hline 10. & 3360 & 2 & 4,4 \\
\hline 11. & 3456 & 1 & 2,2 \\
\hline 12. & 4320 & 1 & 2,2 \\
\hline 13. & 4608 & 1 & 2,2 \\
\hline 14. & 4704 & 2 & 4,4 \\
\hline 15. & 4800 & 2 & 4,4 \\
\hline 16. & 5040 & 1 & 2,2 \\
\hline 17. & 5376 & 1 & 2,2 \\
\hline 18. & 5760 & 1 & 2,2 \\
\hline 19. & 6048 & 1 & 2,2 \\
\hline 20. & 8064 & 2 & 4,4 \\
\hline 21. & 8400 & 1 & 2,2 \\
\hline 22. & 8640 & 1 & 2,2 \\
\hline 23. & 9072 & 1 & 2,2 \\
\hline 24. & 9408 & 3 & 6,7 \\
\hline 25. & 10080 & 5 & 11,1 \\
\hline 26. & 10752 & 1 & 2,2 \\
\hline 27. & 11088 & 1 & 2,2 \\
\hline 28. & 13440 & 2 & 4,4 \\
\hline 29. & 1618 & 1 & 2,2 \\
\hline 30. & 16800 & 2 & 4,4 \\
\hline 31. & 36960 & 1 & 2,2 \\
\hline Total & & 45 & 100 \\
\hline
\end{tabular}

Berdasarkan tabel 1 dapat diketahui durasi bermain game minimal selama 96 jam dan maximal selama 36.960 jam, serta nilai median yaitu selama 5760 jam. Lamanya anak bermain 
game dalam sehari tertinggi adalah 10 jam dan terendah selama 2 jam. Rata -rata mereka bermain game dalam sehari selama 5 jam.

\section{Tabel 2 Distribusi Frekuensu Hasil Pemeriksaan Tajam Penglihatan}

\begin{tabular}{lcc}
\hline Mata Kanan & Jumlah & Persentase \\
\hline Tidak Normal & 20 & 44,4 \\
\hline Normal & 25 & 55,6 \\
\hline Total & 45 & 100 \\
\hline Mata Kiri & Jumlah & Persentase \\
\hline Tidak Normal & 19 & 42,2 \\
\hline Normal & 26 & 57,8 \\
\hline Total & 45 & 100 \\
\hline
\end{tabular}

Hasil pemeriksaan tajam penglihatan berdasarkan tabel 4.2 dapat diketahui untuk mata kanan yang termasuk kategori normal sebanyak 25 orang (55.6\%) dan yang termasuk dalam kategori tidak normal sebanyak 20 orang $(44 . \%)$.

Sedangkan untuk mata kiri yang temasuk dalam kategori normal sebanyak 19 orang $(42.8 \%)$ dan yang termasuk dalam kategori tidak normal sebanyak 26 orang (57.2\%).

\section{Grafik 1 Distribusi Frekuensi Tajam Penglihatan dan Durasi Bermain Game Online}

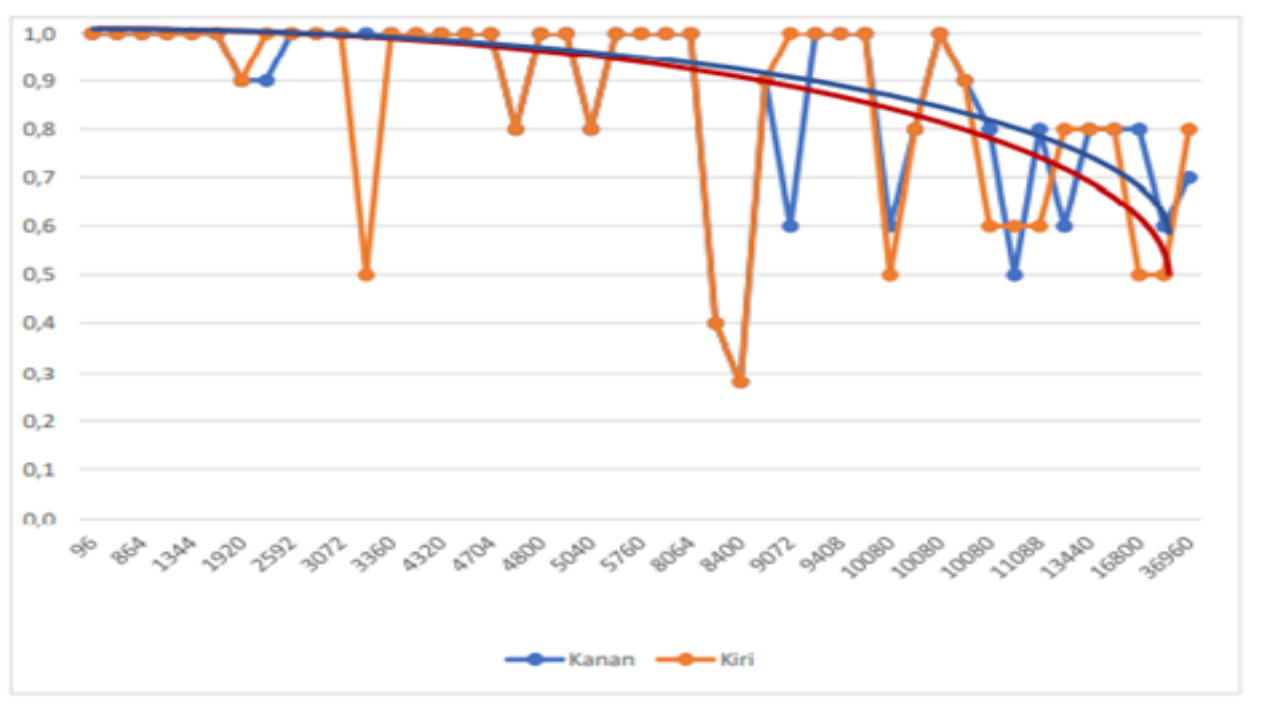

Berdasarkan grafik 1 distribusi frekuensi menunjukan trend atau gambaran, semakin tinggi durasi bermain game online terjadi penurunan tajam penglihatan walaupun tidak signifikan.

\section{B. Pembahsan}

Berdasarkan hasil penelitian yang disajikan pada tabel 4.1 yang mendeskripsikan tentang durasi bermain game terendah selama 96 jam dan tertinggi selama 36.960 jam, serta Jurnal Penelitian Kesehatan STIKes Dharma Husada Bandung nilai median yaitu selama 5760 jam. Lamanya anak bermain game dalam sehari tertinggi adalah 10 jam dan terendah selama 2 jam. Rata -rata mereka bermain game dalam sehari selama 5 jam. Hal ini dikarenakan permainan game online itu membuat pemainnya selalu ingin mengulangi dan penasaran untuk menyelesaikan level demi level permainan sehingga durasi bermain game selalu akan bertambah dalam kurun waktu yang lebih lama. Hal ini sesuai dengan pendapat dari 
JURNAL SEHAT MASADA VOLUME XV

Prot, Anderson etc yang menyatakan bahwa salah satu dampak negative dari bermain game online yaitu "Menimbulkan efek ketagihan, yang berakibat melalaikan kehidupan nyata. Sosialisasi dengan teman jadi berkurang, dan merasa sulit untuk berhubungan dengan orang lain".

Hasil pemeriksaan tajam penglihatan yang dilakukan peneliti pada responden seperti yang tertuang pada tabel 4.2 yang menunjukkan bahwa persentase antara mata yang normal dan yang tidak normal pada mata kanan dan kiri hampir sama yaitu kategori tidak normal untuk mata kanan sebesar $44.4 \%$ dan untuk mata kiri sebesar $42.2 \%$ sedangkan kategori normal untuk mata kanan sebesar $55.6 \%$ dan untuk mata kiri sebesar 57.8\%. Menurut Jeffrey Anshel 2007, salah satu penyebab turunnya tajam penglihatan dikarenakan melihat ke layar monitor, laptop atau televise dalam waktu yang lama. . Ketika menatap layar, tanpa disadari mata akan jarang berkedip dan ini dapat menyebabkan mata kering dan iritasi. Studi menunjukkan, frekuensi berkedip berkurang hampir sebanyak 70 persen ketika seseorang menggunakan perangkat digital. Dan pengguna komputer akan menderita ketegangan mata digital atau Digital Eye Strain (DES).

Berdasarkan hasil grafik distribusi frekuensi menunjukan trend atau gambaran, semakin tinggi durasi bermain game online terjadi penurunan tajam penglihatan walaupun tidak signifikan. Terlihat dari durasi bermain game mulai dari 96 jam sampai dengan 4800 rata-rata tajam penglihatan hasil pemeriksaan adalah 1,0 (normal) walau ada 4 responden yang mengalami penurunan tajam penglihatan. Sedangkan mulai dari 8400 jam sampai dengan 36960 jam terlihat adaya penurunan tajam penglihatan.

Berdasarkan teori yang dituliskan oleh Jeffrey Anshel, OD, dalam buku Visual Ergonomics in the Workplace yang menyatakan bahwa penggunaan computer atau aktivitas didepan layar monitor dalam sehari lebih dari 400 menit berisiko mengalami ketegangan mata digital atau digital eye strain (DES) dengan gejala DES meliputi mata lelah dan penglihatan kabur, dan jika terus-menerus terjadi maka dapat menyebabakan penurunan tajam penglihatan. ( Jeffry Anshel,2007)

\section{KESIMPULAN}

1. Lamanya anak bermain game dalam sehari tertinggi adalah 10 jam dan terendah selama 2 jam.

Rata -rata mereka bermain game dalam sehari selama 5 jam.

2. Distribusi frekuensi hasil pemeriksaan tajam penglihatan untuk mata kanan dan kiri menunjukkan terbanyak dalam kategori normal sebanyak 25 orang $(55.6 \%)$ untuk mata kanan dan sebanyak 26 orang (57.8\%) untuk mata kiri.

3. Hasil grafik distribusi frekuensi menunjukan trend atau gambaran, semakin tinggi durasi bermain game online terjadi penurunan tajam penglihatan walaupun tidak signifikan. Terlihat dari durasi bermain game mulai dari 96 jam sampai 
JURNAL SEHAT MASADA VOLUME XV

dengan 4800 rata-rata tajam penglihatan hasil pemeriksaan adalah 1,0 (normal) walau ada 4 responden yang mengalami penurunan tajam penglihatan. Sedangkan mulai dari 8400 jam sampai dengan 36960 jam terlihat adaya penurunan tajam penglihatan.

\section{DAFTAR PUSTAKA}

Eko, G., S.H, R., Hermawan, A., \& Achmad, S. (2009). Internet Game Online. Makalah.

Esposito , N. (2005). A Short and Simple Definition of What a Videogame Is . DiGRA.

Fachrian, Rahayu, Nasen, Rerung, Pramesti, \& Sari. (2009). Prevalensi Kelainan Tajam Penglihatan Pada Pelajar SD "X" Jatinegara Jakarta Timur. Majalah Kedokteran Indonesia.

Fanzi, L., Anggorowati, L., \& Heriana , C. (2016). Skrining Kelainan Refraksi Mata Pada Siswa Sekolah Dasar Menurut Tanda Dan Gejala. Journal of Health Education.

Fauzi, L., Anggorowati, L., \& Heriana, C. (2016). Skrining Kelainan Refraksi Mata Pada Siswa Sekolah Dasar Menurut Tanda dan Gejala. Journal of Health education.

Hidayat, A. (2010). Metode Penelitian Kesehatan Paradigma Kuantitatif. Jakarta: Heath Books.

Hussain1, Z., Griffiths2, M. D., \& Baguley, T. (2012). Online gaming addiction: Classification, prediction and associated risk factors. informa Healthcare.

Ilyas, S. (2014). Ilmu Penyakit Mata Edisi 5. Fakultas Kedokteran Universitas Indonesia.

Juneti, Bebasari, E., \& Nukman, E. (2015). Gambaran Faktor-Faktor Yang Mempengaruhi Gangguan Tajam Penglihatan Pada Anak Sekolah Porotu, L. I., Joseph, W. B., \& Sondakh, R. C. (2014). Faktor-Faktor Yang Berhubungan Dengan Ketajaman Pengllihatan Pada Pelajar Sekolah Dasar Katolik Santa Theresia 02 Kota Manado.

Pravita. (2010). Skrining Penglihatan ( Visus ) Tahun Sekolah Dasar. Respati.

Prot, S., Anderson, C. A., Gentile , D. A., Brown, S. C., \& Swing, E. L. (2014). The Positive and Negative Effects of Video Game Play. Oxford University Press.

Rabbetts, R. B. (2016). Clinical Visual Optic. London, United Kingdom: Elsevier Health Sciences.

Rudhiati, F., Apriany, D., \& Hardianti, N. (2015). Hubungan Durasi Bermain Video Game dengan Ketajaman Penglihatan Anak Usia Sekolah. Skolastik Keperawatan.

Sugiyono. (2017). Metode Penelitian Kuantitatif, Kualitatif, dan R\&D. Bandung: Alfabeta.

Sujarweni, V. W. (2014). Metodologi Penelitian Keperawatan. Gava Media.

Dasar Kelas V Dan Kelas VI Di SDN 017 Bukit Raya Pekan Baru Tahun 2014. JOM FK Volume II No.2.

Maksus, A. I. (2016). Standar Prosedur Pemeriksaan Refraksi untuk Refraksionis Optision ( Diploma Optometris ). Fakultas Kedokteran Universitas Indonesia.

Notoatmodjo, S. (2015). Metodologi Penelitian Kesehatan. Rineka Cipta.

Oktavianti, E. W. (2017). Hubungan Frekuensi Bermain Game Online Terhadap Kemampuan Internasional Pada Remaja Di Kecamatan Bobotsari Kabupaten Purbalingga. Hasil Penelitian Skripsi. 